\title{
Understanding Women's Psychological Well-Being in Post- Natural Disaster Recovery
}

\author{
Andi Muthia Sari Handayani ${ }^{1}$, Nurdin Nurdin ${ }^{2}$ \\ ${ }^{1}$ Senior Lecturer Department of Islamic Counseling, Faculty of Philosophy, Humanities, and Communication, \\ ${ }^{2}$ Professor Department of Islamic Economic and Business Institut Agama Islam Negeri (IAIN) Palu, Indonesia
}

\begin{abstract}
This study aims to understand psychological conditions of women during post-disaster recovery in Palu city Indonesia. The ethnic women in Palu city are known as the bulonggo (backbone), which describes their role, function, and position in the family. The focus of this study is to examine the psychological aspects of the wellbeing of Kailinese women, especially those who become victims of natural disasters and have lost their possessions. We conducted a survey on 200 women who live in two districts which experience severe earthquake and liquefaction. Through a psychological well-being scale adapted from Ryffand Keyes, the result was analyzed using factor analysis and interview methods. The findings indicate that among six dimensions of wellbeing proposed by Ryffand Keyes, personal growth and positive relationship are the most significant contributing factors to Kailinese women well-being during post-disaster recovery. The findings highlight the important of building personal growth and positive relationship among women community to develop their ability to recover from natural disaster distress. More importantly, as the personal growth and positive relationship contribute to Kailinese women's well-being, their roles as family backbone (bulonggo) in economics and social is also strengthened.
\end{abstract}

Key Words: women's psychological wellbeing, resilient, happiness, post-natural disaster

\section{Introduction}

Reverberating mental and behavioral health consequences occur when the physical forces of natural disaster collide with a vulnerable human population. Women are often found the most vulnerable ones in many cases of natural disaster consequences in term of physical, psychological, economic, and social, but the psychological impacts have been found as more expansive for women in term of scope, more extended in time, and frequently more debilitating in severity than the injurious physical impacts of natural disaster ${ }^{1}$. After a natural disaster, women psychological well-being is often lower than men due to the lost they experience ${ }^{2}$. However, women are considered to have better ability to recover from psychological stress in particular when women get better social support and the sense of purposes ${ }^{3,5}$. As such women better women psychological well-being increase their salient in facing social and economic challenges in supporting their family survival.
Previous Studies argue that factors enhancing women mental well-being and resilience after natural disaster are mostly related the natural environment, meaningful activities, social activities ${ }^{5}$, positive social interaction $^{6}$, social integration ${ }^{7}$, family cohesion $^{8}$, attention from friends ${ }^{9}$. Vernon, Dillon, \& Steiner ${ }^{10}$ also report that the ability to actively respond to disasters with positive forces such as gratitude and optimism can also prevent women from higher levels of trauma. Women are considered to have the strength and resilience to face all difficulties and develop positive meanings in life. In adverse condition, such positive meaning of life can lead women to psychological wellbeing ${ }^{11,12}$.

In this study, psychological wellbeing is understood in a broader context. The meaning of psychological wellbeing has been described as the ability of individuals to accept themselves as they are, form warm relationships with others, be independent of social pressures, control the external environment, have meaning in life, and realize their potential in an ongoing 
way $^{27}$. Thus, individuals who can accept themselves as they are despite being affected by a disaster can get back up and independently achieve psychological wellbeing. Well-being is also considered linked to experiences in family life, to work and other community activities ${ }^{13}$, to religious involvement, spirituality and personal meaning for life ${ }^{14,15}$, to a life rich in purpose and meaning, continued growth, and quality ties to others ${ }^{16}$.

The psychological impacts of natural disasters are widespread, expand across a spectrum of severity, extend along a range of duration, and relate to the nature of the disaster event. The psychological consequences of disasters are spawned by, and directly proportional to, the degree of exposure to hazards, loss, and change, the "forces of harm" that characterize natural disasters. ${ }^{1}$

Studies on disaster impact to women life $\mathrm{f}^{5,17,18}$ found that physical illness, loss of a family member, and pessimistic expectations were associated with adverse psychological sequelae. During post disaster period, women often experience to feel disappointment and other negative emotions in their lives, but their ability to manage distress is very important to feel mentally strong, which has an impact on the emergence of their positive emotions ${ }^{1,19}$. Psychological wellbeing is also related to the ability of individuals to function properly and effectively, accompanied by good feelings, so that they can generate positive emotions ${ }^{20}$.

Similarly, when women develop emotional potential, they can positively change their level of psychological wellbeing which means women who manage their positive emotions have better psychological wellbeing ${ }^{21}$. For example, maintaining a connection to others in the aftermath of disaster can be healing for individual woman and her community. In another word, avoiding isolation and increasing social support is an important factor in building women resilience. ${ }^{17}$

Even though, many studies to understand women psychological wellbeing have been conducted, but research related to the women psychological wellbeing post natural disaster is scarce, in particular studies related to women who play role as families backbone during post disaster recovery ${ }^{5}$.

This study, therefore, examines the psychological wellbeing of women in Kalinese tribe in Central
Sulawesi Indonesia after the natural disasters on September 28, 2018. Kalinese is the largest tribe in Central Sulawesi, and most of the victims come from this tribe. This research will provide an understanding of the psychological wellbeing of Kalinese women as families backbone (bolongo) who are strongly influenced by the natural disaster.

This study uses psychological and cultural perspectives as a theoretical lens. In this paper, the author will answer the following questions: What are the dominant factors affecting the psychological wellbeing of Kalinese women in the aftermath of the disaster, and how significant the cultural and socio-cultural values of the tribe contribute to Kailines women's psychological wellbeing?

This paper is structured as follows: after the introduction, a literature review will be presented. Then, in the third section, the methodology is discussed; subsequently, in the fourth section, the authors present the results, which are then followed by the discussion in the fifth section. Conclusions and limitations of the study will be presented in the sixth and final section.

\section{Material and Method}

The study involved 200 Kalinese women who were at refugee camps in Petobo and Balaroa districts. The Petobo and Balaroa districts are two districts that were swept away by liquefaction and killed more than four thousand people during a deadly earthquake on 28 September 2018. The process of selecting participants used purposive sampling, with subjects divided into 74 respondents in Balaroa and 126 women in the Petobo refugee camp. The age range of the subjects in this study was between 18 to 71 years old, where 56.4 percent of subjects were in the range of early adulthood, 39 percent in middle adulthood, and 4.5 percent elderly.

Other data collected was the education level of research subjects; the categorization of Kalinese women was as follows: 36 elementary school level, 60 junior high school level, 94 senior high school level, and ten bachelor's degree level. The explanation was stated in the graph as follow: 


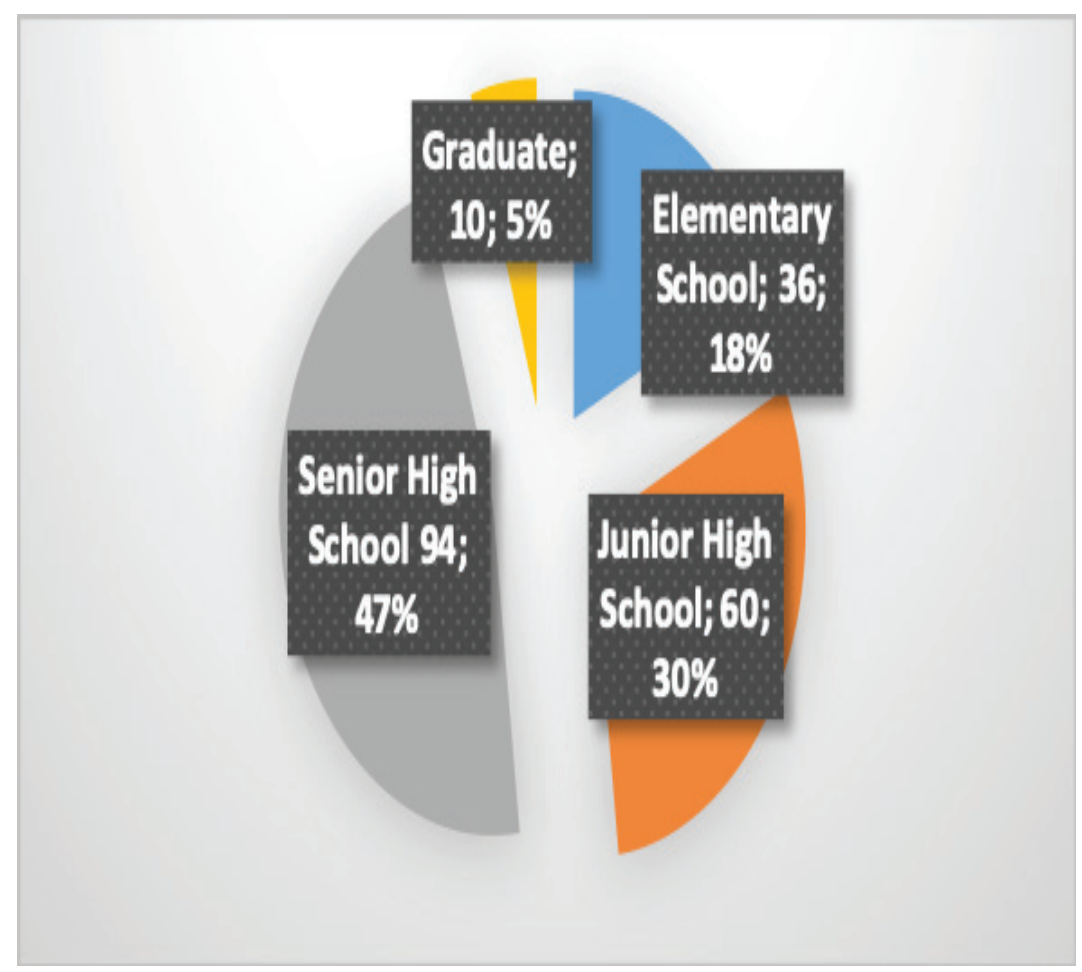

Figure 1: Categorization of Education Level of Research Subjects

Besides, data on Kalinese women who were working is 43 people, and who did not work is 157 people. An Explanation is illustrated through the following graph:

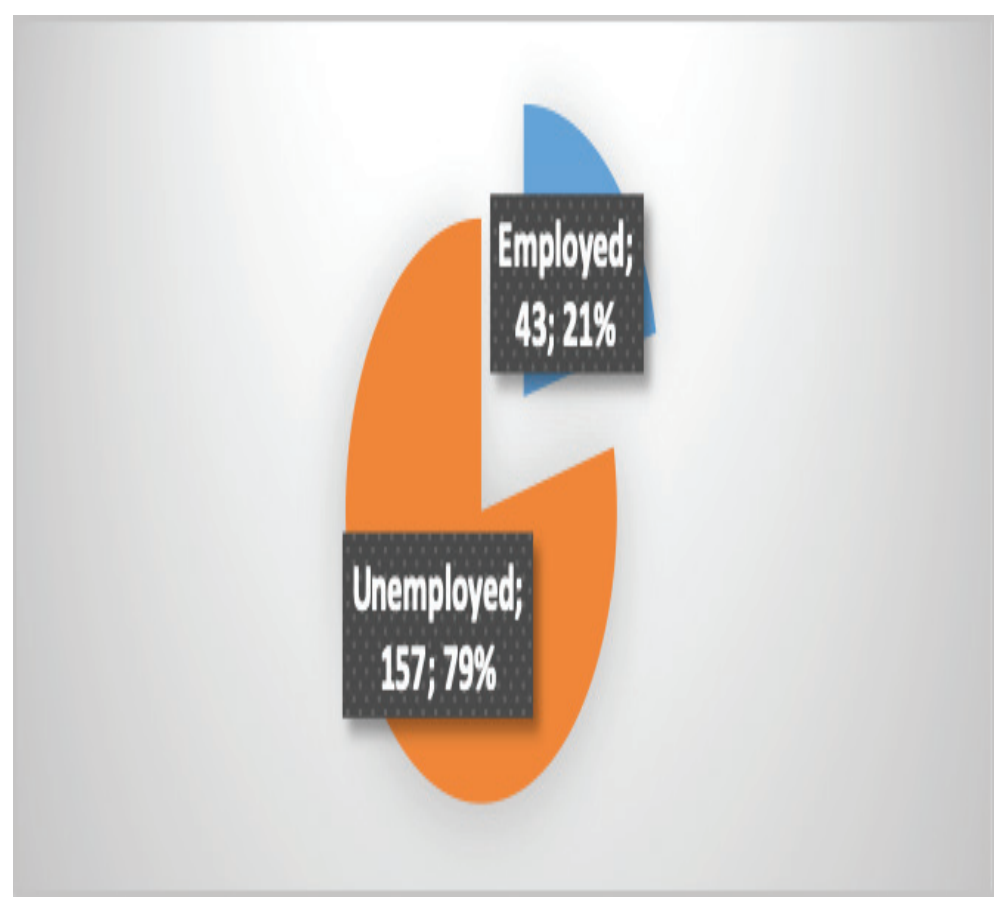

Figure 2: Categorization of Job Status of Research Subjects

The stages of data analysis used in this study began with the validity and reliability tests as prerequisite tests. Next, the researchers used exploratory factor analysis (EFA). The basic consideration of using this technique is that the researcher wants to know the dominance of psychological wellbeing factors that have appeared in Kalinese women since the disaster. 


\section{Results}

\section{Factor and Rotation Test}

The core process of factor analysis to extract a set of variables that have been tested was carried out after KaiserMeyer-Olkin test (KMO) Measure of Sampling Adequacy (MSA). The results of the extraction are shown in the table 1 below:

Table 1: Results of Exploratory Factor Analysis Tests with Psychological Well-being Scale

\begin{tabular}{|c|c|c|}
\hline Variables & Initial & Extraction \\
\hline Independence & 1,000 & .427 \\
\hline Environmental Control & 1,000 & .546 \\
\hline Personal Growth & 1,000 & .532 \\
\hline Purpose of life & 1,000 & .535 \\
\hline Self-acceptance & 1,000 & .690 \\
\hline Positive relationship with other people & 1,000 & \\
\hline
\end{tabular}

Note communalities

The table 2 shows that the autonomy variable is 0.427 which means 42.7 percent of the variance of the autonomy variable cannot be explained in the factors formed. The environmental control variable is 0.541 , or as much as 54.1 percent of the variance of this variable can be explained in terms of the factors formed. Furthermore, the variable personal growth with a value of 0.546 or 54.6 percent of the variance of the variable personal growth can be explained in the factors formed. The rest of the life purpose variable of 0.532 or 53.2 percent of the variance of this variable can be explained in terms of the factors formed. The self-acceptance variable is represented in the form of 0.535 or 53.5 percent, which can be explained in the factors formed. Meanwhile, the positive relationship of variable is indicated by 0.690 or 69.0 percent. The results of total variance test are depicted in the table 2 below:

Table 2. Total Variant Test Results

\begin{tabular}{|c|c|c|c|c|c|c|c|c|c|}
\hline \multirow{2}{*}{ Variables } & \multicolumn{3}{|c|}{ Initial Eigen values } & \multicolumn{3}{|c|}{ Extraction Sums of Squared Loadings } & \multicolumn{3}{|c|}{ Rotation Sums of Squared Loadings } \\
\hline & Total & $\begin{array}{c}\% \text { of } \\
\text { Variance }\end{array}$ & $\begin{array}{c}\text { Cumulative } \\
\%\end{array}$ & Total & $\begin{array}{c}\% \text { of } \\
\text { Variance }\end{array}$ & Cumulative\% & Total & $\begin{array}{c}\% \text { of } \\
\text { Variance }\end{array}$ & Cumulative\% \\
\hline 1 & 2,067 & 34,444 & 34,444 & 2,067 & 34,444 & 34,444 & 1,774 & 29,564 & 29,564 \\
\hline 2 & 1,204 & 20677 & 54,510 & 1,204 & 20677 & 54,510 & 1,497 & 24,946 & 54,510 \\
\hline 3 & .786 & 13,099 & 67,609 & & & & & & \\
\hline 4 & .743 & 12,390 & 79,999 & & & & & & \\
\hline 5 & .710 & 11,827 & 91,826 & & & & & & \\
\hline 6 & .490 & 8,174 & 100,000 & & & & & & \\
\hline
\end{tabular}


Data from the table 2 above show that six components represent variables, where the determination of values is based on the SPSS test> 1 . Then the variance that can be explained by factor 1 which is 2,064 divided by 6 components and multiplied by 100 percent, and the result obtained is 34,444 , while factor 2 is 1,204 divided by 6 components and multiplied by 100 percent, and the result obtained is 20,067 , so the total of the two factors is $34,444+20,067=67,609$ percent. Thus, the total value to be taken is $>1$, namely factors 1 and 2 .

The next stage is to determine each variable that is included in any factor. The rotation test results is presented in the table 3 below:

Table 3. Rotation Test Results

\begin{tabular}{|c|c|c|}
\hline \multirow{2}{*}{} & \multicolumn{2}{c|}{ Component } \\
\cline { 2 - 3 } & \multicolumn{2}{|c|}{299} \\
\hline Independence & .581 & .407 \\
\hline Environmental Control & .738 & .023 \\
\hline Personal growth & .061 & .727 \\
\hline Purpose of Life & & \\
\hline Self-Acceptance & .715 & \\
\hline Positive Relationship with Others & .043 & \\
\hline Note Extraction Method: Principal Component Analysis. Rotation Method: Varimax with Kaiser Normalization. a. Rotation \\
\hline
\end{tabular}

The table 3 above explains the determination of the variables included, in which factors are determined through the largest correlation value, which means the personal growth, self-acceptance, environmental control, and independence more correlated with factor 1. Meanwhile, the variable positive relationships with others and life goals are correlated at a factor of 2 . This is shown in the table 4 below:

Table 4. Factor Forming Test Results

\begin{tabular}{|c|c|}
\hline \multirow{2}{*}{ Factors } & Variable \\
\hline \multirow{3}{*}{1} & Personal growth \\
\cline { 2 - 3 } & Self-acceptance \\
\cline { 2 - 3 } & Environmental mastery \\
\cline { 2 - 3 } & Positive relationship with other people \\
\hline \multirow{2}{*}{2} & Purpose of life \\
\cline { 2 - 3 } &
\end{tabular}

The final stage to determine factors is to look at the values in the following component transformation matrix table: 
Table 5. Component Change Test Results

\begin{tabular}{|c|c|c|}
\hline Factors & $\mathbf{1}$ & $\mathbf{2}$ \\
\hline 1 & .813 & 583 \\
\hline 2 & -.583 & .813 \\
\hline $\begin{array}{c}\text { Note Extraction Method: Principal Component Analysis } \\
\text { Rotation Method: Varimax with Kaiser Normalization }\end{array}$ \\
\hline
\end{tabular}

The table 5 shows that data in component 1 , the correlation value is 0.813 , this value being $>0.5$, and in component 2 , the value is 0.813 , being $>0.5$. It can be concluded that the two factors formed are feasible to summarize the six variables analyzed.

\section{Discussion}

The data obtained revealed that the six aspects; personal growth, self-acceptance, environmental control, and independence as well as positive relationships with others and life goals have influenced the formation of psychological well-being of Kalinese women. However, from the six variables, we found that variables personal growth and positive relationship with others play more significantly influence on the formation of the women psychological well-being.

The findings justify earlier studies ${ }^{1,2}$ that personal growth and positive relationship have become dominant factors affecting the psychological well-being of women. We found that Kailinese women build their well-being, mostly through building a positive relationship with one another during the post-disaster recovery process. However, in this study, the personal growth plays a more significant contribution to the development of Kalinese women's well-being. The finding high-lights that Kalinese women have strong personality in fighting life difficulties during post-disaster period.

More importantly, our study shows that Kailinese women characters are reinforced during the post period of disaster where they can determine their potential and develop their quality of life. A strong character base in growing their potential, in turn, makes Kalinese women resilient and still able to explore their potential despite natural disasters befalling them, destroying them and their environment.

Another manifestation of the aspects of Kalinese women's personal growth is the ability to immediately rise from the natural disasters. This fact was obtained from the results of further interviews with the in ${ }^{l}$, who dominated the trading process in traditional markets a week after the disaster. We identify the rise of entrepreneur motives, such as self-dependence and providing monetary support, to support family income as a medium to socially construct their gender roles ${ }^{24}$. As a result, the roles improve their resilient towards pressures from natural disaster effects. In this regards, Sagone and Caroli ${ }^{25}$ stated that resilient people not only easily rise from disaster, but also have psychological well-being.

The functioning aspect of personal growth in postdisaster Kalinese women is inseparable from their legacy philosophy that is believed to be hereditary in Kalinese culture. In an informal interview, we also found that the Kalinese tribe generally treats women as bulonggo, a philosophy that carries meaning as the backbone. Like the backbone, a true Kalinese woman is formed with a belief to keep growing stronger and develop to become strength for her family. This philosophy is in line with theories about aspects of personal growth in psychological well-being: personal growth associated with an individual's ability to grow ${ }^{26}$. Feelings of being able to go through stages of development, be open to new experiences, realize their potential, and make improvements in life ${ }^{27}$.

Our findings confirm Ryan and Deci ${ }^{28}$ study, which states that one of the important aspects of improving well-being is being able to build positive relationships with others. In a study conducted by Keyes ${ }^{27}$ found that age and education also become an indicator for well-being improvement. However, our study found that education has no relationship with psychological well-being. Most of The Kailinese women with lower education levels, even some of them have no formal education, can achieve psychological well-being during post-disaster recovery.

The ability of Kailinese women to build positive relationships with others and have a positive life purpose was not determined by their level of education, but it was determined by social support from their family, relatives, and people around them. The support encourages the women to be confident and establish 
positive relationships with others. Walen and Lachman ${ }^{29}$ said that positive social relationships built by individuals are strongly correlated with resilient psychological wellbeing.

\section{Conclusion}

As we found that the psychological well-being of Kailinese women during post natural disaster recovery was determined by personal growth, selfacceptance, environmental control, independence, positive relationships, and life goals. We recommend psychologists and government agents to support women psychological well-being building through creating the sense of personal growth, environmental control, independence, positive relationships, and life goals.

Acknowledgement: This work was supported by Faculty of Philosophy, Humanities, and Communication, State Institute for Islamic Studies (IAIN) Palu .

\section{Conflict of Interest: Nil}

\section{Funding: Self}

Ethical Clearance: Obtained from Research Centre and Ethical Committee of State Institute for Islamic Studies (IAIN) Palu

\section{References}

1. Shultz, J.M., et al., Psychological Impacts Of Natural Disasters, in Encyclopedia of Natural Hazards, P. Bobrowski, Editor. 2013, Springer Netherlands: Netherlands. p. 779-791.

2. Van Willigen, M., Do Disasters Affect Individuals, Psychological Well-Being? An Over-Time Analysis of the Effect of Hurricane Floyd on Men and Women in Eastern North Carolina. International journal of mass emergencies and disasters, 2001. 19(1): p. 59-83.

3. King, L.A., et al., Resilience-recovery factors in post-traumatic stress disorder among female and male Vietnam veterans: Hardiness, postwar social support, and additional stressful life events. Journal of Personality and Social Psychology, 1998. 74(2): p. 420-434.

4. McGrath, L., et al., The process of recovery in women who experienced psychosis following childbirth. BMC Psychiatry, 2013. 13(1): p. 341.
5. Ampuero, D., et al., Using mental well-being impact assessment to understand factors influencing wellbeing after a disaster. Impact Assessment and Project Appraisal, 2015. 33(3): p. 184-194.

6. Smith, B.W. and A.J. Zautra, Vulnerability and resilience in women with arthritis: Test of a twofactor model. Journal of Consulting and Clinical Psychology, 2008. 76(5): p. 799-810.

7. Moen, P., D. Dempster-McClain, and R.M. Williams, Social Integration and Longevity: An Event History Analysis of Women's Roles and Resilience. American Sociological Review, 1989. 54(4): p. 635-647.

8. McClure, F.H., et al., Resilience in Sexually Abused Women: Risk and Protective Factors. Journal of Family Violence, 2008. 23(2): p. 81-88.

9. Dunn, L.B., A. Iglewicz, and C. Moutier, A Conceptual Model of Medical Student Well-Being: Promoting Resilience and Preventing Burnout. Academic Psychiatry, 2008. 32(1): p. 44-53.

10. Vernon, L.L., J.M. Dillon, and A.R. Steiner, Proactive coping, gratitude, and posttraumatic stress disorder in college women. Anxiety Stress Coping, 2009. 22(1): p. 117-27.

11. Frankl, V.E., Man's Search for Meaning: Revised and updated 09 ed. 2006, Boston: Beacon Press.

12. Padesky, C.A. and K.A. Mooney, Strengths-Based Cognitive-Behavioural Therapy: A Four-Step Model to Build Resilience. Clinical Psychology \& Psychotherapy, 2012. 19(4): p. 283-290.

13. Ryff, C.D., Psychological Well-Being Revisited: Advances in the Science and Practice of Eudaimonia. Psychotherapy and Psychosomatics, 2014. 83(1): p. 10-28.

14. Fry, P.S., Religious involvement, spirituality and personal meaning for life: Existential predictors of psychological wellbeing in community-residing and institutional care elders. Aging \& Mental Health, 2000. 4(4): p. 375-387.

15. Chamberlain, K. and S. Zika, Religiosity, Meaning of Life, and Psychological Well-Being, in Religion and Mental Health, J.F. Schumaker, Editor. 1992, Oxford University Press: Oxford. p. 138-148.

16. Ryff, C.D. and B.H. Singer, Know Thyself and Become What You Are: A Eudaimonic Approach 
to Psychological Well-Being. Journal of Happiness Studies, 2008. 9(1): p. 13-39.

17. Vujanovic,A.A. andM.W.Gallagher, Psychological Impact of Natural Disasters in Adults. 2017, Department of Psychology, University of Houston: Houston.

18. Sharma, S. and A. Sahu, Development, Characterization, and Evaluation of Hepatoprotective effect of $<i>$ Abutilon indicum $<$ / $i>$ and $<i>$ Piper longum $</ i>$ Phytosomes. Indian Journal of Social Psychiatry, 2015. 31(1): p. 29-36.

19. Shooshtari, S., et al., The mental health needs of women in natural disasters: A qualitative study with a preventive approach. Journal of Family Medicine and Primary Care, 2018. 7(4): p. 678-683.

20. Suresh, A., M. Jayachander, and S. Joshi, Psychological Determinants of Well Being Amongadolescents. Asia Pacific Journal of Research 2013. 1(11): p. 120-134.

21. Nelis, D., et al., Increasing emotional competence improves psychological and physical well-being, social relationships, and employability. Emotion, 2011. 11(2): p. 354-66.

22. Linley, P.A., et al., Measuring happiness: The higher order factor structure of subjective and psychological well-being measures. Personality and Individual Differences, 2009. 47(8): p. 878884.

23. Shela, C.P., D. Yeni, and M.Y.B. Juliana, Correlation between Subjective Well-Being and Psychological Well-Being among University
Students, in 4th International Conference on Public Health 2018. 2018: Indonesia. p. 46-46.

24. Goswami, K., B. Hazarika, and K. Handique, Sociocultural motivation in women's entrepreneurship: Exploring the handloom industry in Assam. Asian Journal of Women's Studies, 2019. 25(3): p. 317 351.

25. Sagone, E. and M.E.D. Caroli, Relationships between Psychological Well-being and Resilience in Middle and Late Adolescents. Procedia - Social and Behavioral Sciences, 2014. 141: p. 881-887.

26. Garcia, D., A. Al Nima, and O.N.E. Kjell, The affective profiles, psychological well-being, and harmony: environmental mastery and selfacceptance predict the sense of a harmonious life. PeerJ, 2014. 2: p. e259-e259.

27. Ryff, C.D. and C.L. Keyes, The structure of psychological well-being revisited. J Pers Soc Psychol, 1995. 69(4): p. 719-27.

28. Ryan, R.M. and E.L. Deci, Self-determination theory and the facilitation of intrinsic motivation, social development, and well-being. Am Psychol, 2000. 55(1): p. 68-78.

29. Walen, H.R. and M.E. Lachman, Social Support and Strain from Partner, Family, and Friends: Costs and Benefits for Men and Women in Adulthood. Journal of Social and Personal Relationships, 2000. 17(1): p. 5-30. 